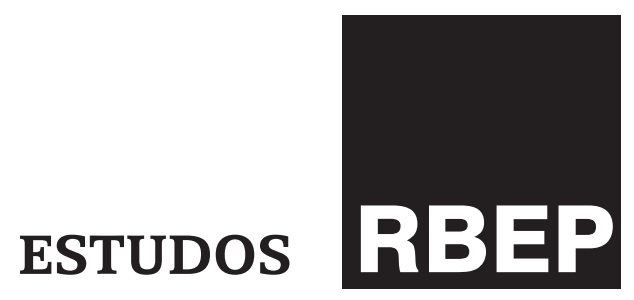

\title{
Ações afirmativas: o critério racial e a experiência da Universidade Federal do Rio Grande do Sul
}

Michele Barcelos Doebber

Gregório Durlo Grisa

\section{Resumo}

Analisa o Programa de Ações Afirmativas da Universidade Federal do Rio Grande do Sul (UFRGS) e as mudanças efetivadas a partir da criação de programas de apoio a sua permanência. Utiliza observações e registros de campo. Justifica-se pela efervescência que as políticas afirmativas provocaram na Universidade e pelo envolvimento dos autores no planejamento e nas ações do Programa. Com base nos dados disponibilizados pela Universidade e nas interpretações realizadas, diagnostica-se o aumento do ingresso de estudantes negros de escola pública, a subutilização de cotas raciais, o aumento de ações que visam à permanência e a falta de diálogo interétnico.

Palavras-chave: ação afirmativa; racismo; universidade. 


\section{Abstract \\ Affirmative actions: the racial criteria and the Rio Grande do Sul Federal University experience}

The study analyzes the Rio Grande do Sul Federal University Affirmative Actions Program and the changes since the creation of access and permanence programs. It utilizes observation and camp registers. This is justified by the impact of the affirmative policies in the University as well as the authors' participation in the planning of the Program. Based on data analysis, it was diagnosed the rise of the public school black students access, the racial quotas subutilization, an increase of permanence actions and lack of interethnic dialogue.

Keywords: affirmative actions; racism; university.

O presente artigo se propõe a discutir o tema das ações afirmativas, tendo o critério racial como orientador de políticas públicas que promovam a reversão das desigualdades étnico-raciais. Inicialmente, construímos uma retomada histórica fazendo referência à sustentação do racismo com base legal e a sua justificativa científica e, em seguida, debatemos brevemente sobre a construção da subjetividade da população negra no modelo de formação do Estado brasileiro.

Analisar a implementação e o desenvolvimento do Programa de Ações Afirmativas da Universidade Federal do Rio Grande do Sul (UFRGS), bem como as mudanças efetivadas por meio de investimentos e medidas que estão sendo implantadas pela gestão da Universidade para aperfeiçoar as ações afirmativas, é o principal objetivo deste artigo. Traremos ainda, no interior do trabalho, algumas explicações sobre o formato adotado pela Universidade e as contextualizações acerca do cenário político que se instaurou antes e depois da adoção das ações afirmativas.

Este documento foi produzido a partir de pesquisas realizadas pelos autores e do efetivo envolvimento destes em duas comissões que atualmente se ocupam do Programa de Ações Afirmativas na UFRGS, quais sejam: Comissão de Acompanhamento dos Alunos do Programa de Ações Afirmativas e Comissão ad hoc de Avaliação do Programa de Ações Afirmativas. ${ }^{1}$ As análises empreendidas foram realizadas a partir de informações disponibilizadas pela Universidade e de dados produzidos para as pesquisas desenvolvidas.

O processo que levou à implantação do Programa de Ações Afirmativas na UFRGS, desde o início das discussões, em 2005, com a
${ }^{1}$ Além dessas comissões, há a Comissão de Acesso e Permanência do Estudante Indígena, que não será foco deste artigo. 
${ }^{2}$ O Grupo de Trabalho Ações Afirmativas foi articulado, em 2005, por estudantes de diferentes cursos de graduação, militantes dos movimentos e organizações sociais vinculados a lutas antirracistas e professores. Em 2006, tornou-se um Projeto de Extensão (Lopez, 2009).

${ }^{3}$ A Comissão Especial de Ações Afirmativas Cepe/Consun foi criada no ano de 2006 a partir do processo institucional desencadeado pela Reitoria, em um contexto de reivindicações, com o objetivo de elaborar uma proposta de Ações Afirmativas para a Universidade. Neste mesmo ano a Reitoria organizou um ciclo de seminários sobre Ações Afirmativas, Ingresso e Vestibular (Sito; Ferreira; Rodrigues, 2008). criação do Grupo de Trabalho Ações Afirmativas ${ }^{2}$ e da Comissão Especial Ações Afirmativas ${ }^{3}$ Cepe/Consun, em 2006, até a aprovação do programa no ano de 2007, foi marcado por tensões, negociações e impasses que refletiam os conflitos no interior da instituição. Dentre os impasses, podemos destacar a modalidade de ação afirmativa a ser adotada (se reserva de vagas ou não), a relevância e legitimidade do recorte racial e o item a ser eleito como caracterizador do critério social (se por renda ou por anos de estudo na escola pública).

A proposta final, aprovada em junho de 2007, resultou na Decisão 134/2007 do Conselho Universitário (Consun), que institui, por um período de cinco anos, o Programa de Ações Afirmativas na modalidade de reserva de vagas a ser implantado a partir do vestibular de 2008. No sistema UFRGS, do total de vagas disponíveis para ingresso por concurso vestibular em cada curso, 30\% são reservadas para candidatos egressos do Sistema Público de Ensino Fundamental e Médio, e destes, a metade, no mínimo, será garantida a estudantes autodeclarados negros. Além disso, foram criadas, no ano de 2008, dez novas vagas para o ingresso de candidatos indígenas, distribuídas nos cursos conforme decisão das comunidades às quais pertencem em acordo com a Universidade.

\section{O critério racial na construção de políticas públicas}

Por que a questão racial se torna central na elaboração de políticas públicas, hoje? Com vista a justificar que o critério racial é passível de ser tomado como item prioritário na elaboração de políticas públicas e que este é um elemento fundamental na estrutura das desigualdades do País, é importante que desenvolvamos argumentos que sustentem essa perspectiva.

Primeiramente, é necessário destacar a construção da subjetividade do sujeito negro brasileiro levando em conta os aspectos políticos e econômicos da história escravista do Brasil, aspectos esses que têm vida no cotidiano das relações sociais de modo distinto, dependendo do meio social e da região em que o sujeito vive. Logo após, no exercício de desprender a situação da população negra contemporânea dos processos vividos e herdados da escravidão, procuramos compreender como as relações inter-étnicas se apresentam no Brasil e como o fenômeno do racismo vem se modificando, tendo como pano de fundo o debate das ações afirmativas.

Temos como base os estudos de Maria da Consolação André (2008), no que diz respeito à construção da subjetividade de afro-brasileiros, ao referir que "a constituição da subjetividade ocorre na objetivação que é dada nos embates relacionais da vida social que são acontecimentos da história da civilização." (André, 2008, p. 63). Portanto, não nos referimos a processos individuais e nem relativos estritamente à consciência. A subjetivação contempla elementos psicológicos e identitários, sendo entendida pela autora 
Como um processo constitutivo do sujeito humano que engloba aspectos corporais, intelectuais, emocionais, sociais e econômicos, pois, enquanto constitutivo, tal processo permite formas diferenciadas de subjetividade e objetividade relacionadas ao mundo psíquico e ao mundo material, o que o torna complexo e passível de busca de compreensão, pois se configura num fenômeno que deve ser olhado como tal (André, 2008, p. 61).

Outra referência que buscamos para nos apoiar, na tentativa de não separar a dimensão da construção da consciência dos processos do mundo material, é o militante e intelectual Frantz Fanon (2008, p. 28), entendendo que

[...] a verdadeira desalienação do negro implica uma súbita tomada de consciência das realidades econômicas e sociais. Só há um complexo de inferioridade após um duplo processo: inicialmente econômico; em seguida, pela interiorização, ou melhor, pela epidermização dessa inferioridade.

A concepção expressa pelo autor nos parece extremamente fértil para discutirmos a dialética raça-classe, bem como para apreendermos o quanto tais dimensões estão interligadas na organização e no desenvolvimento de uma sociedade. Neste momento, porém, a utilizamos para entender a construção da subjetividade do sujeito afro-brasileiro, que é diferenciada da de todos os outros grupos étnicos que formam a população brasileira.

Na escravidão, o negro ocupava lugar central no processo produtivo. As relações econômicas de grande e médio porte, internas e com outros países, dependiam da força de trabalho escrava para se desenvolverem. Era sinônimo de status social para os senhores de fazenda e para os negociantes ter um número elevado de escravos - isso demonstrava poder político e econômico. O ser humano negro, por quase três séculos, era uma mercadoria no Brasil; podia servir de moeda de troca e, ao mesmo tempo, era a força motriz fundamental do sistema.

Portanto, no decorrer da história, "o papel ideologicamente constituído que lhe foi dado é de um ser inferior em todos os aspectos do desenvolvimento - intelectual, emocional, econômico e social." (André, 2008, p. 36). Esse papel é enraizado no imaginário das pessoas de todas as classes sociais, incorporado e reforçado tanto pelo Estado como pela ciência da época.

Referente ao Estado, um dos principais meios de exercício de poder e de discriminação sobre o povo negro foi a legislação, primeiramente a imperial, que era direta e tendenciosa, e, depois, as tácitas da República, que, ao nada dizerem, também negavam ao negro a possibilidade de ascensão social. Podemos destacar aqui o significado de leis fundamentais que promoveram a exclusão do negro no Brasil.

Com a instituição da Lei n ${ }^{\circ}$ 601, de 1850, conhecida como Lei de Terras, ${ }^{4}$ que dispõe sobre as terras devolutas do Império, ocorre uma ação que marginaliza o povo negro. Ao decretar que as terras só seriam obtidas por meio da compra ou que seria considerado proprietário aquele
4 As leis do Império aqui citadas podem ser encontradas no site: http://www.planalto.gov.br/ccivil_03/Leis/LIM/_Quadro-LIM. htm. 
5 Eugenia é um termo cunhado em 1883 por Francis Galton (1822-1911), significando "bem nascido". Galton definiu eugenia como o estudo dos agentes sob o controle social que podem melhorar ou empobrecer as qualidades raciais das futuras gerações, física ou mentalmente. Em outras palavras, melhoramento genético. (Goldim, 1998) que legalizasse suas terras em cartórios oficiais, pagando certa quantia em dinheiro para a Coroa, descaracterizou-se toda a situação geográfica do território nacional.

Desse modo, os quilombos, que existiam em grande número no litoral, foram tidos como ilegais, e, aos poucos, seus territórios foram comprados e sua população expulsa. Em um artigo intitulado "A origem do latifúndio no Brasil", João Pedro Stédile (2000) afirma que

[...] a principal consequência social da Lei de Terras de 1850 é que
manteve os pobres e negros na condição de sem-terra e, por outro
lado, legalizou, agora como propriedade privada, as grandes extensões
de terra, na forma de latifúndio. Todos os antigos concessionários da
Coroa, com a vigência da Lei de Terras, corriam aos cartórios ou às
casas paroquiais que mantinham registros, pagavam certa quantia
pela terra e legalizavam suas posses. Assim, imensas áreas, antes de
propriedade comunal-indígena, depois apropriadas pela Coroa, agora
eram finalmente privatizadas nas mãos de grandes senhores, que
se transformaram de amigos da Coroa em senhores das terras, em
latifundiários.

Poderíamos ainda mencionar a Lei do Ventre Livre, de 1871, que, além de desestruturar a família negra, ao separar os filhos dos pais, ainda tirava toda e qualquer responsabilidade dos senhores de escravos para com as crianças que nasciam "livres" a partir daquela data. Há também a Lei dos Sexagenários, de 1885, que expurgava os velhos escravos com mais de 60 anos das fazendas com o pretexto de deixá-los livres, mas imensa maioria, por não ser mais produtiva, passou a viver nas ruas, marcando, então, os primórdios da mendicância. Ainda temos, já na Primeira República, o Decreto 528, das Imigrações Européias de 1890, que reabre o Brasil para os imigrantes europeus com o intuito de preencher as vagas de trabalho abertas pela industrialização, de continuar o processo de branqueamento da população e proibindo a entrada de negros e asiáticos no País, salvo com a autorização do Congresso.

Os exemplos trazidos são conhecidos e possuem uma abrangência nacional. Também poderíamos mencionar aquelas leis que existiam no interior do País, leis municipais e estaduais que podem soar absurdas hoje, mas que foram feitas por pessoas do poder público, e sabemos que, em determinadas regiões do Brasil, o rodízio de pessoas e famílias exercendo tal função é muito pequeno até nossos dias. Em alguns lugares, os negros só podiam frequentar as "vendas", os armazéns ou os mercados se fossem comprar, mas deveriam logo sair, como pode ser visto, por exemplo, no código de posturas de 1885 da cidade de São João da Boa Vista, São Paulo: "É proibido ao negociante de molhados consentir em seus negócios pretos e cativos sem que estejam comprando. O comerciante sofrerá multa ...". (Gebara, 1986 apud Bertulio, 2007, p. 73).

Em relação à sustentação científica do racismo, sobre a qual fizemos menção anteriormente, nos referimos aos estudos ligados à questão racial que foram feitos do século 17 até as experiências nazistas pautadas na concepção imposta como científica, de eugenia. ${ }^{5}$ 
Maria da Consolação André (2008) desenvolve um breve histórico desses estudos, que são de caráter político-social e, também, clínico-biológico; retrocede às obras de Hume, que em 1776 já declarava que os negros eram naturalmente inferiores, passando pelo iluminismo e pelo "bom selvagem" de Rousseau, que, apesar dessa concepção em relação à raça, foi um dos mais progressistas de seu tempo. A autora ainda estende sua pesquisa até a craniologia técnica e a antropologia criminal, que tinha sua referência em Césare Lombroso e procurava provar o caráter genético, físico e hereditário dos fenômenos criminais. Corroborando essa ideia, Lilia Ferreira Lobo (2008) destaca que o negro, escravo ou liberto, era considerado um elemento "de raça inferior porque descendente de africanos, viciado, imoral, incapaz para o trabalho livre, criminoso em potencial, inimigo da civilização e do progresso" (Azevedo, 1987 apud Lobo, 2008, p. 215).

A busca por legitimar a inferioridade de negros, índios e asiáticos transcende esse pensamento científico e passa, inclusive, pela literatura, pela história e pelas ciências humanas em geral, que também reproduziram, em grande escala, a hierarquização racial das sociedades e o racismo como componentes culturais. A escravidão e o período pós-abolição foram marcados por uma realidade violentamente desigual, e o universo letrado, os costumes e a construção destes como exercício cultural, corroboravam essa desigualdade.

A formação do povo e do Estado brasileiro tem em seu âmago a escravidão e a marginalização do negro do processo de industrialização na passagem para a sociedade capitalista de classes. Houve ainda a promoção de uma política de branqueamento da população brasileira feita pelo Estado, ao promover uma "política afirmativa" com os imigrantes europeus, subsidiando-os na primeira metade do século 20. A fase colonial antecedente teve características que nascem com as grandes navegações e se estendem até nossos dias; algumas reflexões sobre tal período se fazem necessárias.

A ocupação da América pelos europeus representa uma mudança no rumo da história da humanidade. É somente a partir de então que o poder imperial europeu se consolida, que o próprio modo de produção capitalista acha suas matérias-primas e seus mercados para se desenvolver plenamente. Ao produzir essas transformações de caráter estrutural e econômico, as colonizações também são marcadas por engendrarem um amplo jogo de relações entre diferentes povos e culturas. Assim, nosso exercício aqui é procurar compreender quais foram os critérios de organização desse jogo.

Com a chegada dos europeus colonizadores, cria-se um conjunto de identidades baseadas na ideia de raça; os índios, os mestiços e os negros surgem, na perspectiva moderna, a partir do processo colonizador. Essa distinção racial já não se refere aos aspectos geográficos ou de costumes, mas, eminentemente, à diferença das raças na divisão do trabalho. Aníbal Quijano (2005, p. 36-37) nos diz, em seu artigo "Colonialidade do poder, eurocentrismo e América Latina", que: 
Em primeiro lugar, as diferenças entre conquistadores e conquistados codificaram-se na ideia de raça, ou seja, em uma suposta estrutura biológica diferente, que localizava uns em situação natural de inferioridade em relação aos outros [...]. Na medida em que as relações sociais que se estavam configurando eram relações de dominação, tais identidades (índio, mestiço e negro) foram associadas às hierarquias, lugares e papéis sociais correspondentes a cada um, e interpretadas como determinantes destas e, portanto, do padrão de dominação colonial que se impunha. Em outras palavras, raça e identidade racial foram estabelecidas como instrumentos de classificação social básica da população.

Cientes de que corremos o risco de resumir em demasia a complexidade do problema, queremos propor que o racismo, enquanto ideologia, tem como um dos seus fatores explicativos a sistemática divisão racial do trabalho feita através dos tempos em escala global e, principalmente, na América Latina, no desenvolvimento da sociedade colonial-moderna. O entendimento de que determinadas raças deveriam ser responsáveis por setores de trabalho considerados inferiores construiu "verdades" históricas que ainda estão muito presentes.

O fato de percebermos, na colonização, a ligação direta entre trabalho não remunerado (escravo) e as raças dominadas (índio e negro) torna mais palpável o entendimento sobre quais são as origens da nossa herança cultural. É claro que estamos aqui tratando do aspecto econômico, do domínio pautado no critério de raça, mas também sabemos que isso se estende às instâncias subjetivas, pois esse formato social tinha seus aparatos epistemológicos de justificativa que naturalizavam as relações de exploração.

Ao mesmo tempo em que essas raízes históricas existem e sobrevivem, manifestando-se de formas distintas, temos que encarar a difícil tarefa de separar, teoricamente, essa herança colonial de racismo da escravidão dos processos contemporâneos de discriminação racial. O exercício de domesticar a questão racial feito pelo Estado hoje, por meio do direito, requer dinâmicas de ordens não mais de exploração do trabalho, como na escravidão, onde o negro era a base do sistema produtivo, mas sim de negação de direitos e de espaços de trabalho.

É esse cenário que o século 21 apresenta e que marca um novo tipo de tensionamento da dialética raça-classe. Levando em conta as diferenças fundamentais entre os dois conceitos - quais sejam: classe advém de uma contradição contratual jurídica de trabalho que extrai a mais-valia; raça é fruto de uma relação não jurídica, um exercício de soberania para além do direito -, conseguimos perceber a razão pelas quais demandas de políticas de recorte social são mais facilmente aceitas pelo Estado. A implantação das políticas de ação afirmativa na Universidade Federal do Rio Grande do Sul, que será explorada a seguir, é um exemplo vivo dessa tensão.

Quando nos referimos à noção de raça a entendemos na perspectiva sociológica, ou seja, que raça é um componente do imaginário da contemporaneidade e fruto de um conjunto complexo de fatores culturais e históricos. É por meio dessa noção de raça que muitas pessoas organizam seu pensar sobre o outro e conduzem suas posturas. 
Destacamos isso para afirmar que a argumentação de que raça não existe e a utilização de princípios biológicos e genéticos para responder e naturalizar questões essencialmente históricas é um equívoco até certo ponto ingênuo, mas muitas pessoas contrárias às ações afirmativas ainda se apoiam nesse argumento. No momento em que se discute o critério de raça e renda para configurar as políticas de cotas, alguns cientistas sociais afirmam que raça não existe ou que não é um critério com base científica. Todavia, quando foi feita a divisão social do trabalho no período colonial e, em nossos dias, quando falamos na ocupação dos espaços de poder, o critério de raça ainda é um balizador negativo.

A raça biologicamente é uma só, mas histórica e socialmente, não. O debate sobre o uso do conceito raça se estende no campo sociológico e optamos por sua utilização por entendermos que raça representa a noção real sobre a qual se ergue o racismo. Nisso concordamos com a opinião do professor Antonio Sérgio Alfredo Guimarães (1999, p. 27), quando expõe que

[...] se torna muito difícil imaginar um modo de lutar contra uma imputação ou discriminação sem lhe dar realidade social. Se não for à "raça", a que atribuir as discriminações que somente se tornam inteligíveis pela idéia de "raça"? Atribuindo-as a uma realidade subjacente que não é articulada verbalmente, ou a formas mais gerais e abstratas de justificar estruturas de dominação?

A ideia de raça, portanto, refere-se ao campo ideológico de análise (construção histórica); é um conceito que procura entender os "aspectos subjetivos que orientam ações sociais intencionais" (Guimarães, 1999, p. 31). Há um debate denso na sociologia contemporânea entre os intelectuais antirracistas, militantes e estudiosos em geral em relação à recuperação da categoria analítica de raça. Posicionamo-nos na defesa do uso da categoria raça para organizar e desenvolver a resistência ao racismo em nosso País, acolhendo a ressignificação do termo feita pelo Movimento Negro desde a década de 70.

Ainda apoiados em Guimarães (2002, p. 56), entendemos que o conteúdo de tal categoria deve desenvolver constantemente um aparato científico para reorganizar o conceito de raça, devendo, ao mesmo tempo

\footnotetext{
1) reconhecer o peso real e efetivo que tem a idéia de raça na sociedade brasileira, em termos de legitimar desigualdades de tratamento e de oportunidades;

2) reafirmar o caráter fictício de tal construção em termos físicos e biológicos; e

3) identificar o conteúdo racial das "classes sociais" brasileiras.
}

Pensar raça pelo prisma político e social é um exercício que, ao mesmo tempo, quer relembrar que não há diferenças de caráter biológico entre pessoas negras, brancas, pardas, amarelas, ao contrário do que as teorias científicas do século 19 e as políticas de branqueamento do século 20 
afirmavam; por outro lado, procura elucidar a ideia de que há uma construção cultural, política e social, que estamos chamando de raça, que é critério basilar para o exercício do poder violento, tanto simbólico quanto concreto, por parte do Estado.

A dificuldade de tornar a questão racial uma voz jurídica - ou seja, fazer raça, do ponto de vista positivo de valorização da identidade, ser dita e aceita como lei e fazê-la cumprir - mostra-se também quando o assunto é o reconhecimento das terras de comunidades remanescentes de quilombos. Em muitos casos, essa pauta particular dos quilombolas tem se tornado assunto de segurança nacional e não de direito garantido na Constituição - e o mesmo ocorre com as comunidades indígenas.

As desigualdades existentes ao se fazer um recorte racial são visíveis em qualquer um dos indicadores sociais que queiramos eleger. Lilia Moritz Schwarcz (2001, p. 56) aponta para a existência de um censo do racismo no Brasil e afirma que os dados censitários demonstram claramente o quanto não há, na sociedade brasileira, "sobretudo com relação à população negra, uma distribuição equitativa e equânime dos direitos". Dessa forma, cita uma série de situações de notória evidência de desigualdade racial e práticas de racismo, entre elas: a ocupação dos diferentes setores no mercado de trabalho; o tratamento diferencial, pautado na cor, nas práticas penais brasileiras; a disparidade existente nas taxas de mortalidade infantil e mortalidade adulta segundo os diferentes grupos de cor; assim como a desigualdade de acesso ao ensino.

A Síntese dos Indicadores Sociais (IBGE, 2008), que analisa as condições de vida da população brasileira, traz dados importantes referentes à distribuição da população por cor ou raça no que se refere à escolarização, demonstrando que são significativas as diferenças entre os grupos analisados. Enquanto o percentual de brancos entre os estudantes de 18 a 24 anos de idade no ensino superior no ano de 2007 era de $57,9 \%$, o de pretos e pardos alcançava $25,4 \%$, demonstrando a enorme diferença de acesso e permanência dos grupos raciais neste nível de estudo. Na Região Sul, os dados evidenciam que entre os estudantes de 18 a 24 anos de idade no ensino superior 61,4\% são brancos e 36,8\% são pretos ou pardos.

Tais dados reafirmam a pertinência de políticas afirmativas que contribuam para a diminuição das desigualdades existentes entre os diferentes grupos raciais no que diz respeito ao acesso à educação superior. A seguir, apresentaremos o Programa de Ações Afirmativas da Universidade Federal do Rio Grande do Sul, visando discutir sobre os avanços e as dificuldades da política.

\section{Ações afirmativas na UFRGS}

A modalidade da política de ação afirmativa adotada por meio da Decisão 134/2007 do Conselho Universitário (Consun), por um período de 
cinco anos a iniciar em 2008, é a de reserva de vagas. No sistema UFRGS, do total de vagas disponíveis para ingresso por concurso vestibular em cada curso, 30\% são reservadas para candidatos egressos do sistema público de ensino fundamental e médio, e destes, a metade, no mínimo, será garantida a estudantes autodeclarados negros. ${ }^{6}$ Entende-se por egresso do sistema público de ensino fundamental e médio o candidato que cursou com aprovação, em escola pública, pelo menos a metade do ensino fundamental e a totalidade do ensino médio. Há também reserva de vagas para alunos indígenas, criadas anualmente, e o processo de seleção e ingresso é específico, tendo uma comissão especial de acesso e permanência do estudante indígena responsável por administrar e organizar esse processo.

Com a atribuição de propor medidas a serem implementadas desde o início do primeiro semestre de 2008, no sentido de apoiar e dar assistência aos alunos ingressantes pelo Programa, foi nomeada, a partir da Decisão 134/2007, a Comissão de Acompanhamento dos Alunos do Programa de Ações Afirmativas, composta por representantes docentes, discentes e do quadro técnico-administrativo.

Ao determinar que, dos 30\% das vagas reservadas para alunos que estudaram metade do ensino fundamental e todo ensino médio em escola pública, 15\% devem ser destinadas para estudantes autodeclarados negros, observa-se que o critério da escolaridade se sobrepõe ao racial. O que está em jogo nessa decisão? Um dos propósitos centrais das ações afirmativas que orientaram a demanda construída pelos movimentos sociais que lutaram por tais políticas é o da diversidade racial na universidade. Todavia, essa demanda não foi colocada em primeiro plano, não se tornou critério fundamental, visto que o primeiro pré-requisito é o de ter estudado a maioria dos anos em escola pública.

No processo de apreciação das propostas do programa a ser escolhido pela Universidade e na definição ou não pelo critério racial é que as tensões se tornavam maiores nas reuniões do Conselho Universitário e nos debates entre os professores e a comunidade acadêmica em geral. Ao contrário de outras universidades, como a UnB e a UFSM, a UFRGS não adotou cotas para negros, ou seja, cotas levando em conta somente o critério racial, mas sim, diluiu tal critério no da trajetória escolar. Logo, o Programa de Ações Afirmativas da UFRGS prevê cotas para alunos oriundos de escolas públicas, e, dentro dessa cota, há uma porcentagem reservada para alunos que contemplam um critério de recorte racial negros e indígenas.

Esse fenômeno mostra quão difícil é para o Estado e sua conduta jurídica liberal aceitar a raça como uma possibilidade real condutora de uma política pública. Em casos como esse, é preciso colocar a raça como critério secundário para torná-la uma fala legal. De um modo geral, admite-se que exista racismo no Brasil e que o ensino superior seja um dos locus de disparidade e desigualdade tanto racial como social. Mas, quando se quer transformar a raça em balizador de uma política
${ }^{6}$ A autodeclaração é assinada junto à Comissão de Graduação do curso no momento da matrícula. É também nesse momento que o estudante irá apresentar os documentos comprobatórios de escolarização no ensino público. 
institucional, aparecem argumentos e atitudes de várias ordens que mostram como é demagógica essa aceitabilidade da existência de desigualdades raciais e, também, como a sociedade civil pisa em terreno irregular quando aborda esse tema. E, nesse caso, não é somente a desinformação que pesa, mas todo o acúmulo cultural pejorativo - acerca do papel do negro no Brasil - que as pessoas possuem sem ter clara consciência ou sem carregar pré-conceitos intencionais. É nessa construção que reside um importante pilar da complexidade que o tema das ações afirmativas carrega.

Na tese de doutorado em Antropologia Social, de Laura López (2009), temos uma descrição muito fecunda acerca não só do processo de implantação das cotas na UFRGS, mas também dos debates e das tensões que se deram nos anos anteriores. Na exposição que faz, é possível perceber que muitos movimentos dentro e fora da Universidade já existiam na luta por ações afirmativas. Esse fenômeno demonstra que foi pelo aprofundamento do debate, pela pressão política, por um lado, e, também, pela conveniência do momento histórico, que a UFRGS implantou a política.

A abertura da discussão sobre a diversidade na Universidade, que possui características como a de ser monocromática, monocultural e ainda elitizada, ofereceu espaços não só para o debate étnico racial, mas também para análise sobre a necessidade de uma Universidade pública e popular. Esse fenômeno promovido pelas políticas afirmativas proporcionou que os movimentos sociais populares, como o Movimento dos Trabalhadores Sem Terra (MST), o Movimento dos Trabalhadores Desempregados (MTD) e outros, fossem uma presença mais constante na Universidade.

O modelo de ações afirmativas adotado pela UFRGS tem seus limites, e somos críticos nesse sentido. Tais limites estão relacionados principalmente a duas questões: em primeiro lugar, à dificuldade da Universidade e da sociedade em compreender e aceitar a dimensão racial como um critério central da política, conforme já referido e, depois, a uma adequação do processo seletivo (vestibular e a burocracia que o envolve) com as reais intenções do Programa de Ações Afirmativas. Por processo seletivo entendemos o que antecede o vestibular, sua divulgação, seu custo (ou até isenção da taxa de inscrição para alunos carentes), a adaptação de edital, a prova em si e, principalmente, o pós-vestibular.

Depois do vestibular começa o maior desafio do Programa de Ações Afirmativas, e é exatamente nesse quesito que a UFRGS tem muito a fazer, apesar dos avanços. Garantir o acesso é um primeiro e importante passo, mas é a permanência que deve se tornar o eixo propulsor da política.

Na Tabela 1 podemos observar os números referentes à procura, oferta e ocupação das vagas para ingresso na UFRGS pelo concurso vestibular, conforme a modalidade (se por Ingresso Universal, de Ensino Público ou de Ensino Público Autodeclarado Negro). 
Tabela 1 - Ocupação das vagas disponibilizadas no vestibular da UFRGS, conforme modalidade de ingresso - 2008-2011

\begin{tabular}{|c|c|c|c|c|}
\hline Anos & & Universal & $\begin{array}{l}\text { Ensino } \\
\text { público }\end{array}$ & $\begin{array}{c}\text { Ensino público } \\
\text { autodeclarado } \\
\text { negro }\end{array}$ \\
\hline \multirow{3}{*}{2008} & Inscritos & 23.470 & 10.173 & 1.356 \\
\hline & Vagas ofertadas & 2.978 & 667 & 667 \\
\hline & Vagas ocupadas & 2.997 & 1.020 & 295 \\
\hline \multirow{3}{*}{2009} & Inscritos & 22.785 & 10.341 & 1.427 \\
\hline & Vagas ofertadas & 3.148 & 704 & 704 \\
\hline & Vagas ocupadas & 3.174 & 1.151 & 231 \\
\hline \multirow{3}{*}{2010} & Inscritos & 20.802 & 10.564 & 1.340 \\
\hline & Vagas ofertadas & 3.419 & 771 & 771 \\
\hline & Vagas ocupadas & 3.468 & 1.246 & 247 \\
\hline \multirow{3}{*}{2011} & Inscritos & 23.045 & 11.760 & 1.509 \\
\hline & Vagas ofertadas & 3.460 & 779 & 779 \\
\hline & Vagas ocupadas & 3.514 & 1.239 & 265 \\
\hline
\end{tabular}

Fonte: Site da Comissão Permanente de Seleção da UFRGS: http://www.vestibular.ufrgs.br/

Em 2008 ingressou a primeira turma de estudantes por meio do sistema de reserva de vagas no concurso vestibular. Conforme se pode observar na Tabela 1, dos 1.356 estudantes provenientes do ensino público que se inscreveram para concorrer às 667 vagas reservadas para estudantes de escola pública autodeclarados negros no ano de 2008, 295 foram classificados. Desse modo, dos $44 \%$ das vagas destinadas a esse público foram ocupadas naquele ano; as demais foram preenchidas por estudantes que optaram pelo ingresso na reserva de vagas para escola pública. No ano de 2009, dos 1.427 estudantes do ensino público autodeclarados negros inscritos no vestibular para concorrer às 704 vagas disponíveis, 231 foram aprovados, tendo sido 33\% das vagas destinadas a esse público ocupadas naquele ano. Nos anos de 2010 e 2011 esse percentual permanece praticamente o mesmo, em torno de 33\% de ocupação.

Analisando-se o mecanismo de ingresso via vestibular na política de reserva de vagas tendo em vista os dados apresentados acima, vemos que, de modo geral, a ocupação das vagas destinadas a estudantes de escola pública autodeclarados negros tem sido em torno de um terço das vagas reservadas. Como podemos observar, a baixa ocupação não se deve à pouca procura desse grupo de estudantes, já que o número de inscritos foi, em todos os anos, bastante superior ao número de vagas existentes.

Compreendemos que a baixa ocupação de vagas por esse grupo de alunos se deve ao formato utilizado para a classificação no vestibular, que se utiliza de um ponto de corte $^{7}$ que elimina aqueles candidatos que não obtiveram pontuação suficiente para que sua redação fosse corrigida. Assim, uma política afirmativa que pretende ser inclusiva torna-se excludente já no momento do acesso. No modelo utilizado pela UFRGS, a pontuação nas provas é única (todos disputam com todos), o que é diferente de outras universidades cujo ponto de corte é diferente

\footnotetext{
${ }^{7}$ De modo a tornar viável a correção das redações no concurso vestibular, a UFRGS tem como norma em seu edital: corrigir a quantidade de redações referentes a quatro vezes o número de vagas oferecidas em cada curso. Em um curso que possui 100 vagas, são corrigidas as redações dos 400 candidatos mais bem classificados - todos os demais são eliminados. Dessa forma, pode-se dizer que o ponto de corte seria a média harmônica do último candidato selecionado; nesse caso, o de número 400
} 
8 Para esta análise foram considerados os dados informados pelos estudantes no questionário socioeconômico aplicado anualmente pela Comissão Permanente de Seleção. No ano de 2007, anterior à implementação da reserva de vagas, a informação referente à escolaridade do candidato diz respeito somente à escola frequentada no ensino médio. Desse modo, para fins de comparação, utilizou-se esta mesma informação para os anos subsequentes. Assim, os percentuais de ingresso de estudantes autodeclarados negros não são equivalentes ao percentual de ingresso de estudantes pela reserva de vagas, pois o ingresso nesta modalidade exige, além da comprovação de ensino médio em escola pública, ter cursado metade do ensino fundamental. para alunos candidatos às vagas universais e para alunos candidatos à reserva de vagas.

Tomemos como exemplo alguns cursos de maior prestígio na Universidade. No primeiro ano da implantação do Programa de Ações Afirmativas na UFRGS, tivemos o seguinte cenário: havia 12 vagas para alunos autodeclarados negros no curso de Administração, porém nenhum ingressou, devido à pontuação no concurso vestibular; em Medicina havia 21 vagas para autodeclarados negros, mas nenhum aluno negro foi aprovado, pelo mesmo motivo. Em cursos também considerados nobres, como Biomedicina, Fonoaudiologia e Direito diurno, ocorreu o mesmo fato - nenhum aluno autodeclarado negro ingressou naquele ano.

Já no segundo ano da reserva de vagas, 2009, mesmo possuindo 114 candidatos disputando 21 vagas destinadas a esse público, somente um aluno negro ingressou no curso de Medicina. O que podemos observar é que muitas adaptações devem ser feitas, já que uma das reais intenções das ações afirmativas é promover a diversidade na universidade e fazer com que alunos negros egressos de escolas públicas ocupem os bancos acadêmicos. E, quando as vagas já são limitadas, devemos nos mobilizar e procurar garantir que elas sejam ocupadas por quem realmente contempla o público previsto pela política.

O processo atual da UFRGS, no ano de 2011, é de avaliação da política de reserva de vagas e, também, de seu aperfeiçoamento. A seguir trazemos alguns dados referentes a esta avaliação, entretanto, informações mais detalhadas quanto ao impacto do Programa de Ações Afirmativas no perfil dos alunos ingressantes por meio de concurso vestibular estão sendo produzidas pela Comissão de Avaliação, que deve publicar um relatório ainda este ano. Após o término desta primeira etapa de avaliação, projeta-se seguir com uma análise de caráter qualitativo, com o objetivo de avaliar a permanência dos estudantes que ingressaram pela reserva de vagas.

Conforme apresentado pela Pró-Reitora de Graduação durante o I Seminário de Ações Afirmativas da UFRGS, realizado em 2010, os índices de aprovação no vestibular dos candidatos autodeclarados negros tiveram um aumento significativo após a implementação da reserva de vagas. Em 2007, em torno de $3 \%$ dos estudantes que se declaravam negros foram aprovados no vestibular. Em 2008, esse percentual subiu para 11\% e, em 2009, ficou em $9,8 \% .^{8}$

Sobre a proporção de alunos aprovados provenientes de escolas públicas, em relação ao geral, temos 31\% em 2007, 49\% em 2008 e $47 \%$ em 2009. Portanto, com a reserva de vagas estamos chegando a um cenário em que quase metade dos alunos que ingressam na UFRGS são oriundos de escolas públicas ou cursaram nelas quase a totalidade de sua escolaridade.

Um dado interessante que se apresentou durante as análises da Comissão ad hoc de Avaliação do Programa de Ações Afirmativas, da qual fazemos parte, diz respeito ao número de candidatos inscritos no vestibular da UFRGS, que tem diminuído significativamente nos últimos 
anos (em 2003 eram 44.501 inscritos, passando para 40.816 em 2006 e para 34.555 no vestibular de 2009). ${ }^{9}$

Uma das hipóteses que podem ser levantadas para explicar a diminuição das inscrições para o vestibular diz respeito à conjuntura educacional, já que, nos últimos anos, as vagas no ensino superior aumentaram em todo o Brasil: as universidades têm chegado ao interior do Estado, o ensino a distância cresce com muita velocidade, o ensino técnico também vem sendo expandido e programas preveem bolsas de estudos totais ou parciais em cursos de graduação nas instituições particulares, como o Programa Universidade para Todos (ProUni). Em 2007, no Estado do Rio Grande do Sul, o ProUni disponibilizou 10.038 bolsas, sendo elas parciais ou integrais. Em 2008, foram 10.035 e, em 2009, tem-se um salto para 14.198 bolsas. ${ }^{10}$ Nos dois primeiros anos citados, o número de bolsas ProUni foi duas vezes maior que o número de vagas que a UFRGS ofereceu no vestibular e, em 2009, o número de bolsas ProUni foi três vezes superior.

Esses dados se tornam relevantes se lembrarmos que o público com bolsa do ProUni é o mesmo contemplado pela reserva de vagas na UFRGS: alunos de escola pública e, também, boa porcentagem de bolsas para estudantes autodeclarados negros. Uma significativa parcela desse público alvo que estaria concorrendo ao vestibular da UFRGS encontrou outro meio de cursar o ensino superior através da seleção feita pelo Exame Nacional do Ensino Médio (Enem), que classifica para ganhar as bolsas do ProUni nas instituições particulares.

Um elemento importante percebido nos dois primeiros anos de cotas na UFRGS é que os cursos mais procurados e onde mais entram alunos pela reserva de vagas de autodeclarados negros são os cursos noturnos. Esse fenômeno caracteriza um perfil de candidato que precisa trabalhar e busca o ensino superior no período da noite. Tal fato mostra a importância do oferecimento de cursos noturnos e explica a opção de muitos estudantes pelas universidades privadas, já que estas costumam oferecer maiores possibilidades de escolha de turno de estudo.

\section{Programas de apoio à permanência}

O ponto em que temos observado maiores avanços na UFRGS é na política de apoio pedagógico e na ampliação da assistência estudantil. No ano de 2008, primeiro ano do Programa de Ações Afirmativas, a UFRGS dispunha de diversos programas de assistência estudantil, entre eles: Casa do Estudante, Restaurante Universitário, Bolsa Permanência e Programa Saúde. A partir do Programa Nacional de Assistência Estudantil (Pnaes), instituído em dezembro de 2007, a Universidade ampliou o leque de benefícios, passando a oferecer, no ano de 2009, também a Bolsa Reuni ${ }^{11}$ e, em 2010, Auxílio Transporte, Auxílio Creche, Auxílio Material de Ensino e Auxílio Moradia.

Até 2007, os gastos com assistência estudantil eram recursos que a própria Universidade disponibilizava anualmente, conforme a

\footnotetext{
9 Informação extraída dos Cadernos do Vestibular da UFRGS (Carlos; Meira; Macedo, 2009, p. 9).

${ }^{10}$ Dados extraídos do site: http:// ProUniportal.mec.gov.br/. Acesso em: 10/03/2011.

${ }^{11}$ Bolsa proveniente do Programa de Apoio ao Plano de Reestruturação e Expansão das Universidades Federais.
} 
possibilidade. Após esse ano, com a aprovação do Pnaes, foi instituída uma dotação orçamentária própria para a assistência estudantil, recurso repassado pelo governo federal especialmente para este fim. Tal programa tem significado um aumento expressivo no montante de recursos destinados à assistência estudantil e, em consequência, a ampliação do número de estudantes beneficiados e de serviços disponíveis.

No âmbito da pesquisa, em 2009, foi lançado pelo Conselho Nacional de Desenvolvimento Científico e Tecnológico (CNPq) um edital visando contemplar especificamente bolsas de iniciação científica para alunos ingressantes via Programa de Ações Afirmativas. A UFRGS foi contemplada com 20 bolsas, distribuídas nas diversas áreas do conhecimento, conforme interesse expresso nos projetos dos professores orientadores.

No que tange à graduação, houve desacomodação pelas demandas de evasão e repetência historicamente existentes em alguns cursos da UFRGS, o que se tornou mais visível com o ingresso dos alunos cotistas, segundo a Pró-Reitora de Graduação. ${ }^{12}$ No ano de 2010, foram criados dois projetos: o Projeto de Recuperação e Estudos Intensivos e o Programa de Apoio à Graduação.

O Projeto de Recuperação e Estudos Intensivos (Prei) é um programa piloto desenvolvido pela Faculdade de Matemática; ocorre durante o período de recesso escolar e é oferecido para estudantes que foram reprovados com conceito D na disciplina de Cálculo I, de modo que possam rever conteúdos e recuperar o conceito na disciplina, que apresenta um índice em torno de 30\% a 40\% de repetência. Segundo informações fornecidas pela Pró-Reitoria de Graduação, dos 100 inscritos no Prei no segundo semestre de 2010, 45 foram aprovados na disciplina de Cálculo, sendo considerado um resultado bastante positivo, pois significa que 45 estudantes não precisarão repetir a disciplina no semestre seguinte.

O Programa de Apoio à Graduação (PAG) nasceu no ano de 2010, a partir das demandas trazidas pela Comissão de Acompanhamento dos Alunos do Programa de Ações Afirmativas, espaço onde teve seus primeiros momentos de elaboração e organização. O Programa é coordenado pela Pró-Reitoria de Graduação e realizado em duas modalidades: PAG 1 e PAG 2.

O PAG 1 tem por objetivo apoiar a realização de estudos sobre a retenção e evasão de alunos em cursos de graduação, incentivando com bolsa o professor da instituição que constituir uma equipe para realizar tais estudos. O edital que selecionou 10 projetos para esse programa prevê bolsa para professor responsável, aproveitamento de dois bolsistas de pós-graduação do Programa Reuni e quatro bolsas de monitoria para alunos da graduação. A equipe é formada, portanto, por sete membros.

O PAG 2 tem por objetivo apoiar os estudantes que necessitam de reforço no processo de ensino-aprendizagem em cálculo, física, química, português, inglês e produção de textos acadêmicos e científicos. No âmbito desse projeto, começaram a ser desenvolvidas, em 2010, atividades gratuitas para os alunos de graduação da UFRGS, aos sábados pela manhã e à tarde. O edital desse programa selecionou projetos com bolsa para o 
professor responsável, e a equipe que o executa tem o mesmo formato do PAG 1. Esse programa pretende dar um suporte mais concreto aos alunos que são reprovados ou encontram dificuldades em algumas disciplinas. A avaliação feita até o momento é bastante positiva tanto por parte dos professores quanto dos estudantes que participaram do programa de apoio.

Com a expansão das universidades federais a partir do Reuni - que, apesar de controverso, ${ }^{13}$ vem ampliando o acesso e a permanência na educação superior - a UFRGS, até o momento, já abriu 49 novas vagas para Técnicos em Assuntos Educacionais, cargo de nível superior que tem como principais atribuições planejar, supervisionar, analisar e reformular o processo de ensino aprendizagem. Estes já iniciam alguns projetos de acompanhamento pedagógico dos estudantes de graduação, visando principalmente o combate à evasão e a qualificação da permanência dos estudantes em seus cursos.

Essas são medidas que estão em andamento e marcam certo avanço na política de permanência ainda incipiente na UFRGS. O tema das ações afirmativas ainda é tratado com reserva, e a visibilidade e o fortalecimento da política sofre resistências sistemáticas por setores da comunidade acadêmica. As relações políticas que permeiam o universo de gestores, pesquisadores, funcionários e alunos são de constante tensionamento e cobrança. A demanda pela qualificação do Programa de Ações Afirmativas e pela sua aplicabilidade concreta ainda provoca constrangimentos na universidade, que deveria ser o lugar dos debates mais avançados e progressistas.

\section{Considerações finais}

Já tratamos de expressar que nosso País é racista enquanto Estado e que as desigualdades sociais e raciais são gritantes e notáveis. Tendo clara essa dimensão, é tranquilamente compreensível que a temática das ações afirmativas e as demandas por tais políticas sejam questões presentes em nossos dias. A educação é um dos campos onde é possível notar mais as diferenças sociais e raciais, e há no Brasil o contrassenso entre o que se assegura na lei e a realidade, pois sabemos que a Constituição Federal prevê o direito à educação para todos, e isso como responsabilidade do Estado e da família.

Considerando que a população negra é a maioria da população pobre em nosso País e que nossa história contém ingredientes fartos de discriminação racial institucional, as ações afirmativas nas universidades são medidas totalmente pertinentes e necessárias. Se quisermos desenhar outro quadro ou construir novo rumo para o ensino superior, para os espaços de ciência e, de certo modo, para a sociedade como um todo, políticas com esse perfil podem contribuir de modo significativo.

Sabemos do caráter afirmativo e imediato da reserva de vagas nas universidades e entendemos que a transformação da sociedade transcende esse tema. No entanto, gostaríamos de dizer que essas políticas não são
${ }^{13}$ Há na academia diversas interpretações acerca da proposta do Reuni. Pesquisas indicam que o Programa, ao mesmo tempo em que representa uma expansão quantitativa de vagas no ensino superior, tem promovido, por exemplo, um processo de precarização do trabalho docente (Lima, 2011). 
contrárias a um maciço investimento em educação básica e que elas não provocam uma racialização das relações nas universidades, mas sim uma mínima diversificação.

Por que afirmamos que a presença do povo negro na universidade é positiva e imprescindível? Em um apanhado geral das ciências sociais, das humanas e da educação, campo em que atuamos, as produções que existem são baseadas, em sua imensa maioria, em referências européias (eurocentrismo gnosiológico da modernidade) e não respondem à realidade cada vez mais repleta de novas configurações e angústias. A ciência é divorciada da busca de soluções aos problemas fundamentais das populações que estão mais suscetíveis à violência, ao desemprego, sem o atendimento das suas necessidades básicas. A universidade pública precisa dos alunos afrodescendentes tanto quanto estes precisam dela; novos projetos, novas ideias e um redirecionamento da curiosidade epistemológica, que foi sempre guiada pelo olhar da elite branca brasileira, são ingredientes fundamentais para a promoção das mudanças científicas necessárias.

As populações negras precisam, primeiramente, ser representadas nos espaços de produção científica, ocupar quantitativamente, cada vez mais, esses espaços, e as ações afirmativas vislumbram auxiliar nesse sentido, pois, como nos ensina Karel Kosik (1976, p. 119), "a mudança da função de determinados valores não é o resultado de uma avaliação subjetiva, mas de uma mudança objetiva das relações sociais". O número de negros professores universitários e pesquisadores credenciados em instituições de amparo à pesquisa é ínfimo no Brasil.

Segundo os dados de 2005 do Sistema Nacional de Avaliação da Educação Superior (Sinaes), somente em torno de 1,6\% dos professores universitários de todo o País são negros. A UFRGS se constitui como uma das universidades brasileiras mais desiguais no que diz respeito à distribuição racial dos seus docentes; conforme pesquisa de 2005, dos 2.044 docentes dessa instituição, 1.881 se autodeclararam brancos, 15 amarelos, 32 pardos, 8 negros, 5 indígenas e 103 não declararam sua raça/cor. Considerando esses dados, vemos que não chega a 0,5\% o percentual de professores negros na UFRGS.

Nesse sentido, Carvalho (2006, p. 20-21) indica que

[...] a ausência entre os quadros das universidades brasileiras de acadêmicos negros produzindo conhecimento e reflexão sobre a questão negra na educação deixou essas instituições com pouca capacidade para refletir sobre sua própria política racial e de auto-avaliar-se adequadamente nesse respeito.

Além dessa questão, que ganha ares de médio e longo prazo, a reserva de vagas será um meio para que um grupo étnico significativo ingresse no âmbito da formação superior e, por conseguinte, no mercado de trabalho. Em uma pequena passagem, Florestan Fernandes (1979, p. 72) nos aponta um pré-requisito que se torna um foco de luta real na contemporaneidade: 
As estruturas raciais da sociedade brasileira só poderão ser ameaçadas e destruídas quando "a massa de homens de cor", ou seja, todo elemento negro, puder usar o conflito institucionalmente em condições de igualdade com o branco e sem nenhuma discriminação de qualquer espécie, o que implicaria em participação racial igualitária nas estruturas de poder da comunidade política nacional.

Esse trecho parece extremamente atual, e, quando se fala em estruturas, devemos ter claro que medidas como a implantação de políticas de recorte racial irão sempre enfrentar grande resistência nas camadas conservadoras da sociedade.

As ações afirmativas têm, em sua "comissão de frente", uma importância simbólica, ou seja, elas tratam de algo inovador, que rompe com o invólucro cínico da democracia racial que tanto parcela da mídia como alguns artistas e intelectuais alegam existir no Brasil. Um argumento em favor das ações afirmativas apontado pela professora Arabela Campos Oliven (2009, p. 9) "é o da necessidade de reconhecimento de todos os grupos como iguais". Na opinião da autora,

\begin{abstract}
Na medida em que a forma de seleção nos cursos mais concorridos das universidades públicas deixa de lado uma população tão numerosa como a dos pretos e pardos brasileiros, passa-se a idéia de que o lugar que forma a elite nacional pode prescindir da contribuição de quase metade da população brasileira. Esse argumento tem a ver, também, com o significado simbólico dos modelos para as novas gerações. É importante para os jovens negros e indígenas verem representantes de seus grupos bem-sucedidos como profissionais nas áreas do Direito e da Medicina, por exemplo, nas atividades de pesquisa.
\end{abstract}

As pessoas que passarão a ocupar algumas vagas por meio dessas políticas, de modo geral, têm um perfil diferente daquelas que historicamente ocuparam esses espaços, não encarando isso como uma lógica mecânica. Concordamos com a professora Arabela Oliven quando afirma que, por pertencerem a uma camada social privilegiada, alguns estudantes não cotistas podem mais facilmente se desinteressar por seu curso, tentar novo vestibular para outro curso, trancar a matrícula, pois a sua posição social lhes possibilita esse tipo de opção. Os estudantes cotistas, como temos visto nas pesquisas que desenvolvemos, sabem que não podem desperdiçar a chance que estão tendo, porque "como integrante[s] de um grupo que luta por uma inserção mais equitativa na sociedade brasileira, o comprometimento social dos cotistas parece ser maior" (Oliven, 2009, p. 73).

Na UFRGS vimos nos defrontando com muitos avanços e desafios, o que é inerente ao processo de implantação de uma política nova e complexa. Algumas questões vêm à tona nesse processo; uma delas é como adequar o processo de vestibular - que é seletivo e, por princípio, excludente - com a nova realidade que as ações afirmativas propõem para a universidade. Outra questão necessária de ser pensada pela UFRGS é a de como criar espaços contínuos de diálogo inter-étnico, de acolhimento e de visibilidade da política afirmativa e, por conseguinte, dos sujeitos sociais que, por direito conquistado, estão ingressando na universidade mediante política de 
ações afirmativas repleta de contradições, mas que vem trazendo à tona um debate muito caro para nós, que é o direito de o povo negro no Brasil conquistar políticas públicas e lutar por garantias constitucionais, como fazem as comunidades remanescentes de quilombos.

Esse é um passo essencial no confronto político, mas acompanhar como se materializam as políticas e quais os empecilhos que existem para que elas alcancem seus reais objetivos é também uma prática fundamental. Essa atividade precisa ser cumprida pela academia por meio da pesquisa, e pelos agentes políticos dos movimentos sociais, que são os representantes de um projeto alternativo de sociedade.

O fato sociológico de existir a reserva de vagas para alunos egressos de escola pública e autodeclarados negros na nossa Universidade não tem se resumido a garantir algumas vagas para aqueles que, historicamente, não as ocupariam. Também tem provocado o debate sobre o racismo de modo cada vez mais intenso, e isso não é um mérito simbólico que somente a política de cotas carrega, mas é também fruto de um conjunto de demandas históricas do Movimento Negro.

Por fim, a construção de uma política que toca em uma ferida brasileira tão dolorosa como o racismo carrega consigo a possibilidade de debatermos o porquê de sua existência e o seu sentido em nossos dias. A população negra, em sua maioria, tem uma relação de tensão e distância com o Estado, apesar de existirem avanços no campo jurídico. Tornar realidade e consolidar as conquistas que o movimento negro obteve, como o reconhecimento constitucional das comunidades quilombolas, a obrigatoriedade do ensino da cultura africana, as cotas nas universidades e em concursos, é o desafio contemporâneo. Esse desafio é de todos os militantes sociais, intelectuais, pesquisadores, políticos engajados no compromisso com uma sociedade diferente da que está posta.

As ações afirmativas têm garantido que praticamente metade dos alunos que ingressam na universidade seja egressa de escolas públicas - isso é um fato social relevante. O número de alunos que se declaram pretos e pardos no formulário de inscrição do vestibular (por isso tal nomenclatura de classificação) e estão ingressando na UFRGS mais que duplicou com a reserva. Porém, não devemos entender que isso seja suficiente e que o ingresso desses alunos represente de todo o êxito da política: há inúmeras demandas ligadas à permanência, ao apoio pedagógico, à criação de espaços de diálogo e promoção de visibilidade e, ainda, outros desafios que virão e que devem ser encarados. Para que isso ocorra de modo positivo, a constante pressão política promovida por militantes dos movimentos negros, pelos estudantes, por professores e pesquisadores é fundamental.

\section{Referências bibliográficas}

ANDRÉ, Maria da Consolação. O ser negro: a construção de subjetividades em afro-brasileiros. Brasília: LGE, 2008. 
BERTULIO, Dora Lúcia de Lima. Ação afirmativa no ensino superior: considerações sobre a responsabilidade do Estado brasileiro na promoção do acesso de negros à universidade - o sistema jurídico nacional. In: PACHECO, Jairo Queiroz; SILVA, Maria Nilza da (Org.). O negro na universidade: o direito à inclusão. Brasília: Fundação Cultural Palmares, 2007. p. 51-98.

BRASIL. Lei no 2.040, de 28 de setembro de 1871 (Lei do Ventre Livre). Declara de condição livre os filhos de mulher escrava que nascerem desde a data desta lei, libertos os escravos da Nação e outros, e providencia sobre a criação e tratamento daqueles filhos menores e sobre a libertação anual de escravos. Disponível em:

<http://www.planalto.gov.br/ccivil_03/Leis/LIM/LIM2040-1871.htm>. Lei $n^{\circ}$ 601, de 18 de setembro de 1850 (Lei de Terras).

Dispõe sobre as terras devolutas do Império. Disponível em:

<http://www.planalto.gov.br/ccivil_03/Leis/LIM/_Quadro-LIM.htm>.

Decreto $n^{\circ}$ 528, de 28 de junho de 1890. Regulariza o serviço da introdução e localização de imigrantes na República dos Estados Unidos do Brasil. Disponível em: < http://legislacao.planalto.gov.br/ legisla/legislacao.nsf/b2394d7e1ab9a970032569b9004e148d/f889cf34 50277933032569fa00434d2a?OpenDocument>.

. Lei no 3.270 de 1885 (Lei Saraiva-Cotegipe ou Lei dos Sexagenários). Regula a extinção gradual do elemento servil. Disponível em: < http://www.historiabrasileira.com/ escravidao-no-brasil/lei-dos-sexagenarios/> .

CARLOS, Maria Adélia Pinhal de; MEIRA, Maria Cristina Pastro; MACEDO, Roberto (Org.). Vestibular da UFRGS 2009: provas comentadas; processo de avaliação. Comissão Permanente de Seleção (Coperse)/UFRGS. Porto Alegre: Ed. da UFRGS, 2009.

CARVALHO, José Jorge de. Inclusão étnica e racial no Brasil:

a questão das cotas no ensino superior. 2. ed. São Paulo: Attar, 2006.

FANON, Frantz. Pele negra, máscaras brancas. Salvador: EDUFBA, 2008.

FERNANDES, Florestan. Circuito fechado: quatro ensaios sobre o poder institucional. 2. ed. São Paulo: Hucitec, 1979.

GOLDIM, José Roberto. Eugenia. 1998. Disponível em: < http://www. ufrgs.br/bioetica/eugenia.htm>. Acesso em: 10 mar. 2011.

GUIMARÃES, Antonio Sérgio Alfredo. Classes, raças e democracia.

São Paulo: Editora 34, 2002. 231 p. 
GUIMARÃES, Antonio Sérgio Alfredo. Racismo e anti-racismo no Brasil. São Paulo: Ed. 34, 1999.

INSTITUTO BRASILEIRO DE GEOGRAFIA E ESTATÍSTICA (IBGE). Síntese de indicadores sociais - uma análise das condições de vida da população brasileira. 2008. Disponível em: <www.ibge.gov.br/home/estatistica/ populacao/Condicaodevida/indicadoresminimos/sinteseindicsociais2008/ indic_sociais2008.pdf>. Acesso em: 10 abr. 2011.

KOSIK, Karel. Dialética do concreto. 2. ed. Rio de Janeiro: Paz e Terra, 1976.

LIMA, Kátia. As novas faces da intensificação do trabalho docente no Brasil. In: ENCONTRO BRASILEIRO DE EDUCAÇÃO E MARXISMO, 5., 2011, Florianópolis. Marxismo, educação e emancipação humana. Florianópolis: UFSC/PPGE, 2011. CD-ROM. Disponível em: <http://www.5ebem.ufsc.br/trabalhos/eixo_09/e09d_t002.pdf>.

LOBO, Lília Ferreira. Os infames da história: pobres, escravos e deficientes no Brasil. Rio de Janeiro: Lamparina, 2008.

LÓPEZ, Laura Cecília. "Que América Latina se sincere": uma análise antropológica das políticas e poéticas do ativismo negro em face às ações afirmativas e às reparações no Cone Sul. 2009. 389 f. Tese (Doutorado em Antropologia Social) - Universidade Federal do Rio Grande do Sul (UFRGS), Porto Alegre, 2009.

OLIVEN, Arabela Campos. Ações afirmativas na Universidade Federal do Rio Grande do Sul e o seu significado simbólico. Revista Educação, Santa Maria, v. 34, n. 1, p. 65-76, jan./abr. 2009.

QUIJANO, Aníbal. Colonialidade do poder, eurocentrismo e América Latina. In: LEHER, Roberto; SETÚBAL, Mariana (Org.). Pensamento crítico e movimentos sociais. São Paulo: Cortez, 2005.

SCHWARCZ, Lília Moritz. Racismo no Brasil. São Paulo: Publifolha, 2001.

SITO, Luanda Rejane Soares; FERREIRA, Junara Nascimento; RODRIGUES, Tatiana do Prado. O processo de implementação das ações afirmativas na UFRGS. In: TETTAMANZY, Ana Lúcia Liberato et al. (Org.). Por uma política de ações afirmativas: problematizações do Programa Conexões de Saberes/UFRGS. Porto Alegre: Ed. UFRGS, 2008. p. 119-125.

STEDILE, João Pedro. A origem do latifúndio do Brasil. Revista Pucviva, São Paulo, n. 8, 2000. Disponível em: < http://www.apropucsp.org.br/ revista/r08_r06.htm>. Acesso em: 6 ago. 2009. 
UNIVERSIDADE FEDERAL DO RIO GRANDE DO SUL (UFRGS).

Conselho Universitário (Consun). Decisão no 134/2007, de 29 de junho de 2007. Fica instituído o Programa de Ações Afirmativas, através de Ingresso por Reserva de Vagas para [...] candidatos autodeclarados negros egressos do Sistema Público de Ensino Fundamental e Médio e candidatos indígenas. Disponível em: < http://www.ufrgs.br/consun/leis/ Dec134-07.htm>.

Michele Barcelos Doebber, mestranda em Educação na Universidade Federal de Rio Grande do Sul (UFRGS), é técnica em Assuntos Educacionais da UFRGS e membro da Comissão ad hoc de Avaliação do Programa de Ações Afirmativas e do Núcleo de Estudos em Currículo, Cultura e Sociedade (Neccso) da UFRGS.

micheledoebber@yahoo.com.br

Gregório Durlo Grisa, doutorando em Educação na Universidade Federal do Rio Grande do Sul (UFRGS), é membro da Comissão ad hoc de Avaliação do Programa de Ações Afirmativas e do Núcleo de Estudos, Experiências e Pesquisas em Trabalho, Movimentos Sociais e Educação (Tramse) da UFRGS.

grisagregorio@yahoo.com.br

Recebido em 19 de abril de 2011.

Aprovado em 29 de setembro de 2011. 